\title{
3D Reconstruction of Furniture Fragments from the Ancient Town of Karanis
}

\author{
EIMAN ELGEWELY, University of Alexandria, Egypt
}

\begin{abstract}
Furniture is the most personalized component of architectural space. It reflects or even determines the use of space, as well as the standard of living, the gender, and age of the user. Heirlooms, furthermore, are retainers of memory and social relationships. The raw materials used and the level of skill and craftsmanship necessary to produce furniture speak to the availability of such items for the community. Importation of wood, techniques, or entire pieces of furniture show connectedness with other production centers. Furniture fragments are abundant among the well-preserved archaeological finds from the ancient Greco-Roman town of Karanis, a site located on the arid desert edge of the Fayum basin, Egypt. Objects include furniture legs, boxes, reading tables, and table tops. The University of Michigan mission, which worked on the site for about ten years (1924-1934), had as its main focus the architecture of Karanis. The furnishings of these structure do, however, provide important information and a study of the woodworking, and composition of the pieces has now been undertaken, together with an attempt to place these remains back in their virtual context. The reconstruction of the Karanis furniture provides a major challenge because the fragments belong to various time periods and combine Egyptian, Greek, and Roman influences and tastes. This research is a next phase of the project "Reviving Karanis in 3D," which we started in 2013. In this research, we aim at using state-of-the-art digital technologies to create multiple interpretations of 3D reconstruction of a selection of furniture pieces based on analysis and photogrammetric models of wood furniture fragments from the Karanis collection of the Kelsey Museum of Archaeology, University of Michigan.
\end{abstract}

Key words:

Wooden furniture, Virtual Heritage, 3D Reconstruction, Photogrammetry, Re-contextualization

SDH Reference:

Eiman Elgewely. 2017. 3D Reconstruction of Furniture Fragments from the Ancient Town of Karanis. SDH, 1, 2, 409-427.

D0I : $10.14434 /$ sdh.v1i2.23340

\section{INTRODUCTION}

When the "Reviving Karanis in 3D" project began in 2013, we intended to employ digital technology to visualize what the material aspects of life were like in Karanis town. The excellent preservation of organic materials provided the excavators in the 1920s with good examples of daily-life objects used by Egyptian farmers and land owners in one of the most fertile areas of Egypt, the Fayum basin. The town was founded by Ptolemy II with the aim of settling Greek veterans and to take advantage of the fertile region for agriculture. It lasted under Greek and Roman rule for about seven centuries, from the second century BC to the fifth century AD. Karanis today is a large archaeological site that is

Author's address: Eiman Elgewely, Faculty of Fine Arts, University of Alexandria, Egypt; email: eiman_elgewely@yahoo.com Permission to make digital or hardcopies of part or all of this work is granted without fee according to the open access policy of SDH.

(c) 2017 SDH Open Access Journal 
deteriorating and suffering massive loss of mud brick structures owing to their exposure to the elements starting from the time when they were excavated in the early twentieth century. Ongoing deterioration following large-scale excavation is not only a result of past disregard for preservation, but it continues to create tensions between the need to backfill vulnerable architectural remains and the wish to display cultural heritage for local pride or income from tourism [Barnard et al. 2016]. These conflicting interests highlight the importance of virtual reconstruction as an approach that can either reflect or reconstruct what is no longer extant, or provide virtual access to backfilled remains through augmented reality.

In the first phase of the project, we focused on the study and reconstruction of residential buildings, their interior architectural details, and the open courtyards. The study and documentation of the buildings by the University of Michigan research team in the twenties of the last century and subsequent work by the URU Fayum project (University of California, Los Angeles; Rijksuniversiteit Groningen and University of Auckland) formed a solid basis for our work and helped to accomplish the objectives of the first phase [Elgewely and Wendrich 2015a]. That phase also included the creation of photogrammetric 3D models of some of the Karanis finds from the collection of the Kelsey Museum of Archaeology, Ann Arbor, Michigan, and the placement of these in their proposed original location inside the virtual models [Elgewely and Wendrich 2015b].

Instead of presenting just the architecture, the model also includes the mobile material culture found in the excavated spaces, in order to reflect the personal aspects of space use and life style of the Karanis inhabitants. A more detailed study of the Karanis furniture from other contexts was the next phase in this effort to provide more complete interior details of the houses. To select wooden objects and fragments to go with particular buildings, we made use of the recording and archiving method of the 1920s University of Michigan excavation team. Every object was recorded according to the year of excavation; the level of occupation; the number of the structure or house and the particular room it was found in. The team used the occupation level as a rough chronological indicator, discerning 5 levels of occupation (A-E, in which $A$ is the most recent while $E$ is the oldest; see Table. 1). These levels were not consistent over the site and were mainly dated by papyrus finds and coins. The value of the levels for dating is, therefore, problematic, but most furniture finds can be dated to the early to late Roman Period [Husselman 1979].

Table 1. Approximate dates for the Michigan designated layers.

\begin{tabular}{|c|c|}
\hline Layer & Approximate Date \\
\hline A & Early 4 th to early $6^{\text {th }} \mathrm{C}$. CE \\
\hline B & Early $3^{\text {rd }}$ to early $4^{\text {th }}$ C. $C E$ \\
\hline C - late & Mid $2^{\text {nd }}$ to early $3^{\text {rd }}$ C. $\mathrm{CE}$ \\
\hline C - early & Mid $1^{\text {st }}$ to mid $2^{\text {nd }} C . C E$ \\
\hline $\mathrm{D}$ & Mid $1^{\text {st }} \mathrm{BCE}$ to mid $1^{\text {st }} \mathrm{CE}$ \\
\hline E & Ptolemaic $3^{\text {rd }}$ to mid $1^{\text {st }}$ c. BCE \\
\hline
\end{tabular}

Roman-era furniture outside Egypt in the Roman heartland has been mainly reconstructed from wall paintings and depictions on mosaics, reliefs, vases and other types of illustrations [Mols 2008]. 
Although wood was one of the materials used in abundance in antiquity, it is rarely attested in excavations because of decay and decomposition.

An important source for the reconstruction of wooden furniture of the Roman period is the carbonized furniture from Herculaneum, covered, burnt and ultimately preserved by the charring influence of the lava from the Vesuvius eruption of 79 C.E. In Herculaneum, the use of wood in furniture and furnishings was ubiquitous: furniture, shelves, doors and window shutters have been identified [Mols 1999]. In our reconstructions we relied on the work of Gisela Richter (1966), Stephan Mols $(1999,2008)$ and Roger Ulrich (2007) in their study of Greek and Roman furniture, to understand not only the aesthetic features and design of Greek and Roman furniture but also the construction techniques that had an impact on the product's final appearance. Furthermore, in our study we compared the Greco-Roman furniture fragments with what is known about high-status Egyptian furniture from tomb contexts [Killen 1979; Killen 1994]. The aridity in Egyptian desert sites and rockcut tombs allowed for the preservation of organic materials, including furniture made from wood, matting and leather.

Wood was not abundant in Greco-Roman Egypt and wooden furniture was, therefore, an investment, especially when constructed from hard woods, such as olive. Furniture was often multi-purpose and thus did not determine the function of rooms as clearly as present-day furnishings. Indications of the functions of domestic spaces as "bedroom," "living room," or "dining room" are informed by a Western approach to the use of space, where furniture forms a limitation, as well as an enabler of use. A room that is filled by a king-size bed does not allow for a flexible use of that space, while especially in the smaller lower class houses sleeping mats would have served as impromptu beds in rooms that might function as a workshop or reception area during the day.

\section{KARANIS FURNITURE: MATERIALS AND TECHNIQUES}

From the extant wooden objects and fragments discovered in Karanis, it is evident that furniture was an expensive commodity, used extensively, often repaired and re-used. Furniture was inherited as part of the house and its inventory, as is attested commonly in written documents such as Donationes Mortis Causa [Husselman 1957]. Chests, beds, stools, tables and lamp stands that have been excavated show differences in style, but it is difficult to link this to a particular period, social stratum or cultural group, because of the multi-generational use of these relatively expensive objects. Re-use of architectural elements can be clearly demonstrated, even by looking at the distribution of capitals and pillars. Such re-use certainly can also be considered likely for wooden elements used as part of house construction or furnishing.

The amount of fragmentary furniture recovered during the excavations in Karanis would have been just a small percentage of what had once been in use in any given period. The town was gradually abandoned in the sixth century $\mathrm{CE}$, and intact objects would have been taken away. What would have been left behind were the broken furniture parts, dumped in abandoned basements and garbage heaps. Moreover, during the life of the town most of the discarded wood would have been used as kindling. 


\section{1:412 E. Elgewely}

The wooden finds that display clear features of having been part of furniture show a large variety of use wear, but also signs of craftsmanship, such as tool marks, and a variety of joints. The wood types of the fragments from the Kelsey Museum, used to create the furniture shown in the Karanis model, have not been identified, but wood analysis of comparable material by the URU Fayum project has shown that sycamore, acacia, tamarisk and olive wood were local species that were used to create furniture. Date palm trunks and leaf midribs were used in ceilings, but not in carved and planed wooden objects. These are the same types of local wood as those used in Pharaonic Egypt for making furniture and other objects. All these wood species yield relatively short, thin and curvy stems. Deforestation and the need for tall, strong and straight wood for masts, pillars and wooden coffins necessitated the import of pines and cedars from the region of Byblos in present day Lebanon. In the Roman period, in addition, boxwood, and oak were imported from the Eastern Mediterranean, as well as ebony from the southern regions of present day Sudan and Ethiopia.

Roman furniture closely followed the styles of the earlier Greek and Hellenistic forms and has not been distinguished by specific characteristics or datable styles. The characteristics of the Karanis wooden fragments match those of the Greek and Roman furniture, especially in terms of the proportions, lathed legs and mortise-and-tenon joinery. Most of the items are simple, with minimum decorations or embellishments. They lack decorative inlays with metal or shell, which reflects the economic and social status of the inhabitants of Karanis. Most of the inhabitants were farmers and craftsmen, while some of the larger houses were owned by higher status individuals [Husselman 1979]. This is very different from the elite housing in Pompeii or Herculaneum where furniture was embellished with decorative inlays, bronze or silver embellishments.

The most used woodworking joint in the majority of wooden objects from Karanis is mortise and tenon, a common way to join two pieces of wood, mainly when the adjoining pieces connect at an angle of $90^{\circ}$. The basic mortise and tenon comprises two components: the mortise hole and the tenon tongue (Fig. 1a). The tenon, formed at the end of a piece of wood, is cut to fit exactly into a square or rectangular hole cut into a second wooden piece. Usually, once the joint has been made, both mortise and tenon are hidden. The joint can be strengthened by gluing, or wedging the tenon into the mortise. There are many joint variations, for example the pegged tenon (Fig. 1b), keyed tenon (Fig. 1c), through tenon (Fig. 1d) or the wedged tenon (Fig. 1e). The dovetail tenon (Fig. 1f) is a visible $90^{\circ}$ connection, while the dowel and plug connection (Fig. 1g), is used to connect two parallel planks, as is the biscuit tenon (Fig. 1h).

The choice of the type of joints depends on the required angle, the wood type, the direction of the grain and the stress that the joint will have to endure. The joint also needs to account for the degree to which the wood expands and contracts with changes in temperature and humidity [Ulrich 2007]. Nevertheless, several of the joint types illustrated above were employed in a wide range of uses. The mortise and tenon joint was used extensively in ancient Egyptian and Roman wood working for furniture, ship building and in architecture. The dovetail joint (a very distinctive form of the mortise and tenon) has been attested in very fine furniture, but also in heavy duty wooden constructions [Ulrich 2007]. 


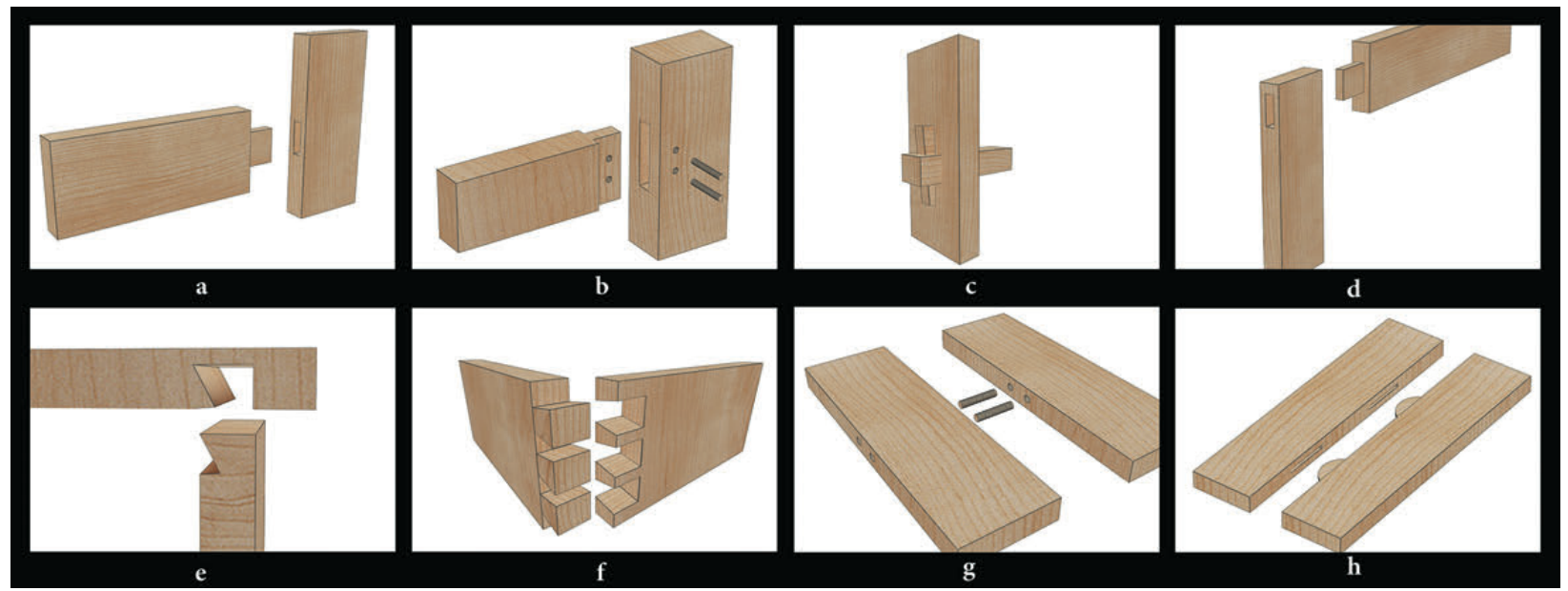

Figure 1. Variety of joints: a) mortise and tenon; b) pegged tenon; c) keyed tenon; d) through tenon; e)wedged tenon; f) dovetail tenon; g) ) dowel and plug tenon; $h$ ) biscuit tenon.

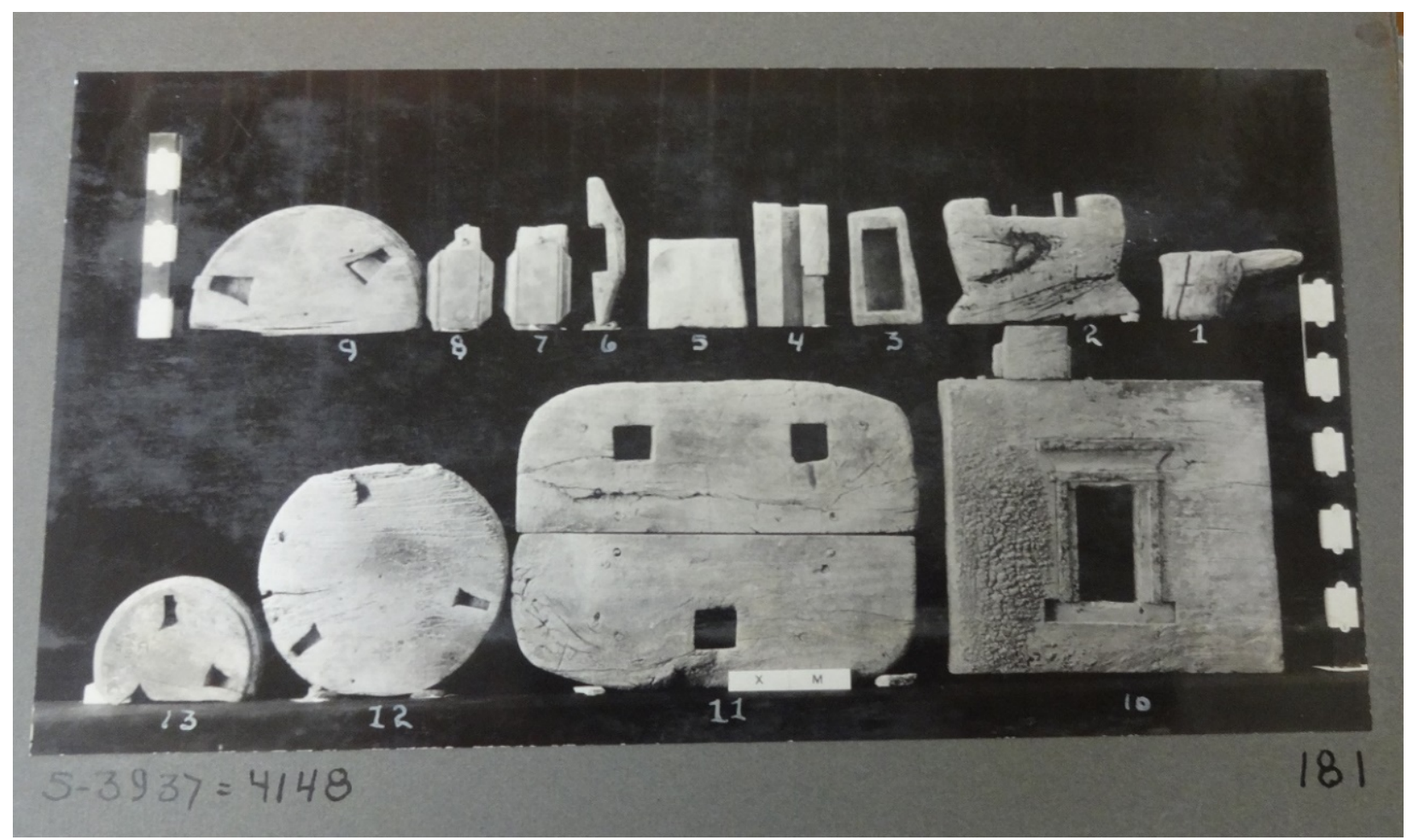

Figure 2. Wooden Furniture Fragments- Karanis Archaeological finds Catalogue- Kelsey Museum of Archaeology (Photo courtesy of Kelsey Museum of Archaeology) 
A comparative study of furniture fragments from Karanis and extant or reconstructed furniture from ancient Egypt and the Greco-Roman world formed the basis for the selection of pieces for the 3D reconstruction approach of the collection of the Kelsey Museum of Archaeology, University of Michigan, Ann Arbor (Fig. 2). The main objectives at this level are: first, to identify the function of each piece; second, to study its woodworking joints; and finally, to complete the missing parts of each piece of furniture.

The study of each piece of furniture in this investigation required the integration of multiple resources, including the comparison of relevant items in several museum collections around the world. Two-dimensional CAD drawings, based on furniture sections, were drawn from multiple references and were then used as a guide to compare them with the photogrammetric models from Karanis, regarding proportions and height, and to facilitate making the depictions of woodworking joints details.

\section{METHOD}

The method was divided in three main phases: creating the 3D digitization of furniture fragments from Karanis; reconstructing the furniture from the fragments; and merging the furniture with the previously created virtual environment of a Karanis house. The workflow contained the following steps:

- Photography of extant furniture fragments with an 18.2 megapixel Sony digital camera. The number of pictures for each fragment ranged from 80 to 450, depending on the size of the object and the level of detail required.

- The photographs were then aligned using Agisoft Photoscan Pro (Structure-from-Motion software).

- The surface and mesh modification and filling of voids in the mesh were done in the program Geomagic (a 3D digital sculpting program)

- The texture was modified in ZBrush (3D digital sculpting and painting program) to create an even surface texture.

- The polygons were then reduced in Agisoft Photoscan to create a low polygonal model to be used later in the virtual model for easier and smoother navigation in real time.

- Then the model was imported once again to ZBrush to generate the UV map and add the grooves, wood grain and surface irregularities (normal map and bump map).

- The models were exported to 3D Studio Max (modeling software) to add the missing parts of the furniture piece to the 3D model of the furniture fragments.

- This low-polygonal model was then brought into the previously created 3D environment of the building using 3D Studio Max. 


\section{INTACT WOODEN FURNITURE}

The intact wooden furnishings from Karanis households were mostly sturdy boxes and provided examples of many of the construction methods used in other types of furniture as well. Most of the woodworking details that we will discuss in the following examples are identical to the standard woodworking joints in ancient Egypt as well as in the Greek and Roman world that were discussed previously. The type of box in Fig. 3 is very common in Karanis. Small boxes were usually employed for storing personal belongings such as wooden combs and jewelery and to convey a certain level of wealth in Karanis. The construction method used to connect the box sides is usually the dovetail wood joint as shown in Fig. If. The photogrammetric 3D model (Fig. 3) was created using 181 photographs.

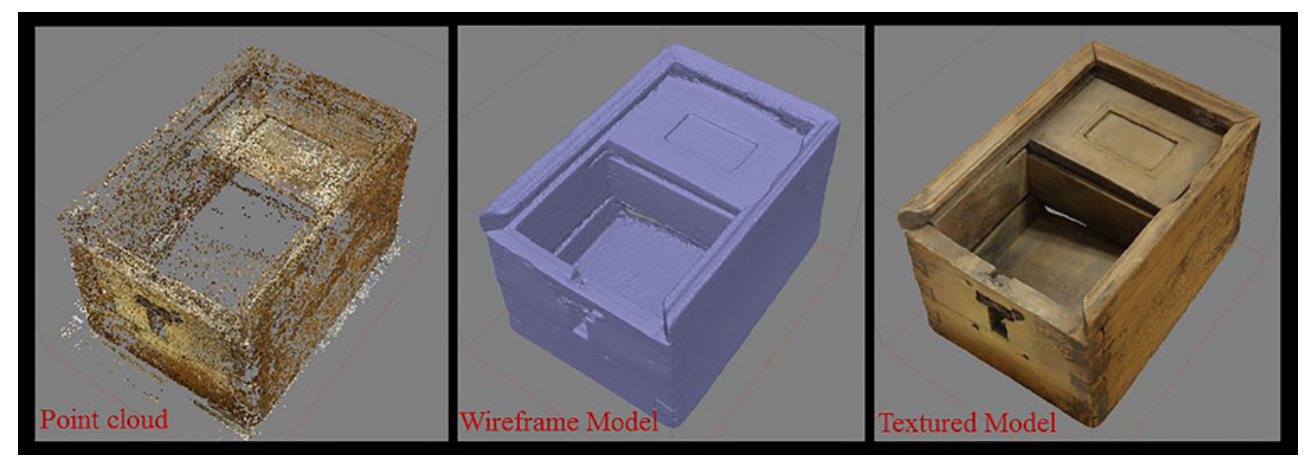

Figure 3. Photogrammetric 3D modeling process from point cloud to textured model.

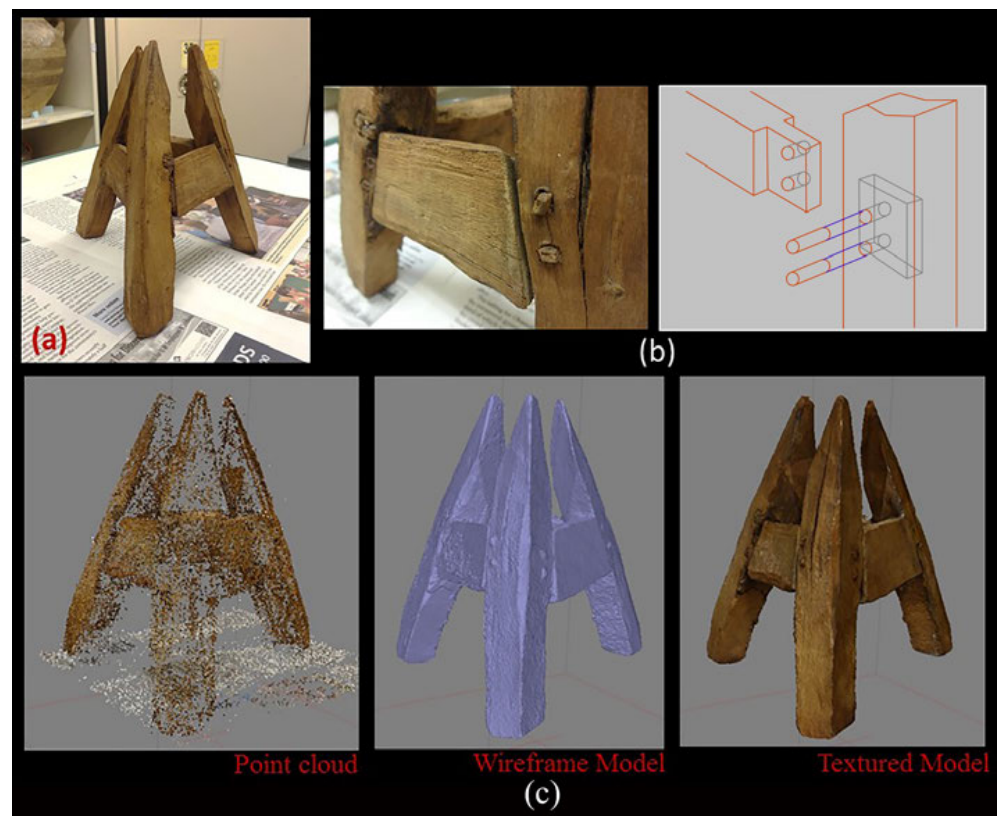

Figure 4a) A wooden lamp stand from Karanis; b) Mortise and tenon joint reinforced with wooden dowels used to connect the sides of the lamp holder; c) Photogrammetric 3D modeling process from point cloud to textured model. 
In almost every Karanis house wooden lamp stands were found, which supported glass cone-shaped oil lamps. These were used to illuminate the interiors, which were dark even during the day, because the windows were small and high up in the wall. The type of woodworking joint used in the lamp holder in Fig. 4a is mortise and tenon reinforced with wooden dowels (Fig. 4b). The photogrammetric 3D model in Fig. 4c was created using 268 photographs.

Several reading tables were found in Karanis, which reflect the importance of reading and a level of literacy among the inhabitants. The table in Fig. 5a belongs to the C-level of occupation, where we can observe a very standard woodworking method; the use of dowel plugs especially in connecting wooden blocks in table tops and benches (Fig. 5b). Another joint used here is the keyed mortise and tenon joint, which is usually used to connect the sides of the furniture piece (Fig. 5c). The photogrammetric 3D model in Fig. 5d was created using 237 photographs.

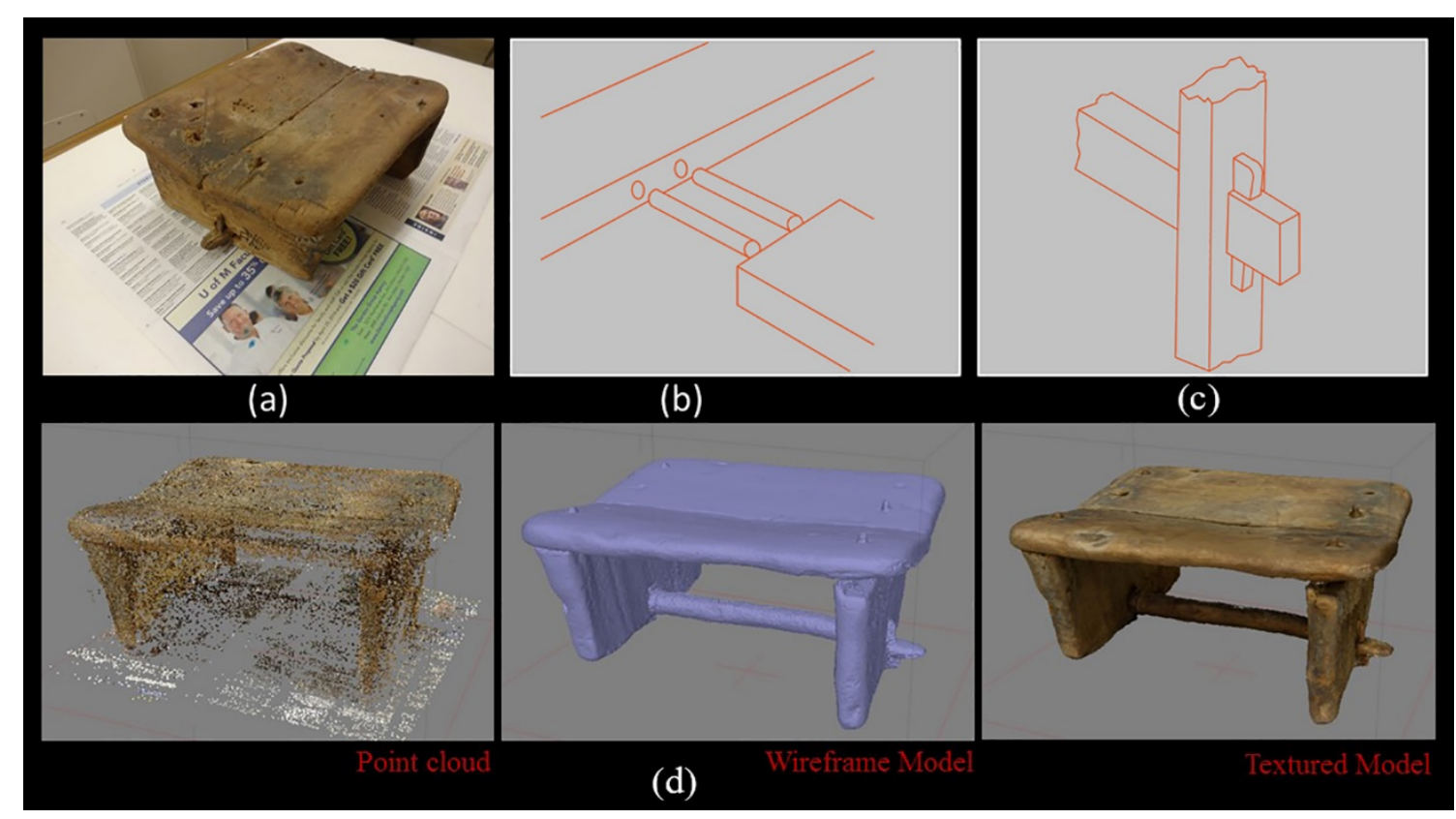

Figure 5. (a) A wooden reading table from Karanis; (b) Dowel plug used to connect the wooden sheets of the table top; (c) Keyed mortise and tenon joint reinforced with wooden dowels used to connect the sides of the reading table; (d) Photogrammetric 3D modeling process from point cloud to textured model.

\section{DIGITAL RECONSTRUCTION FROM FURNITURE FRAGMENTS}

\subsection{Chairs}

The fragment in Fig. 6 (a) is listed in the Kelsey Museum of Archaeology archive as a chair leg and belongs to the $\mathrm{C}$ level (approximately $1^{\text {st }}-2^{\text {nd }} \mathrm{C}$. CE). Its height is $38 \mathrm{~cm}$, and it has two holes from the top and bottom of the back side. In the first instance, this may look like part of a stool, similar to a Greek diphros, a common backless seat. As can be seen in Fig. 6 a and b, the leg has only two 
openings from one side, which would make it difficult to imagine how four legs would have been fitted together. A more likely reconstruction is that of a wooden bench. Such benches are known from high end skeuomorphic furniture in stone, which seem to imitate wooden benches, such as the reconstructed one from Herculaneum depicted in Fig. 7a [Croom 2007]. The Latin term for such an elongated stool was subsellium, in use to seat multiple persons in an average domestic context, but also for seating large groups of people in amphitheaters, vestibules or temples and other gathering places [Ulrich 2007][Ulrich 200.

From the tool marks and notches in the Karanis fragments we can assume that the joints used in the bench were the mortise and tenon for joining the front and back leg, the biscuit joint for joining the wooden parallel planks of the bench seat, and the half dovetail dado for joining the leg with the top of the bench (Fig. 7c, 7d and 7e).

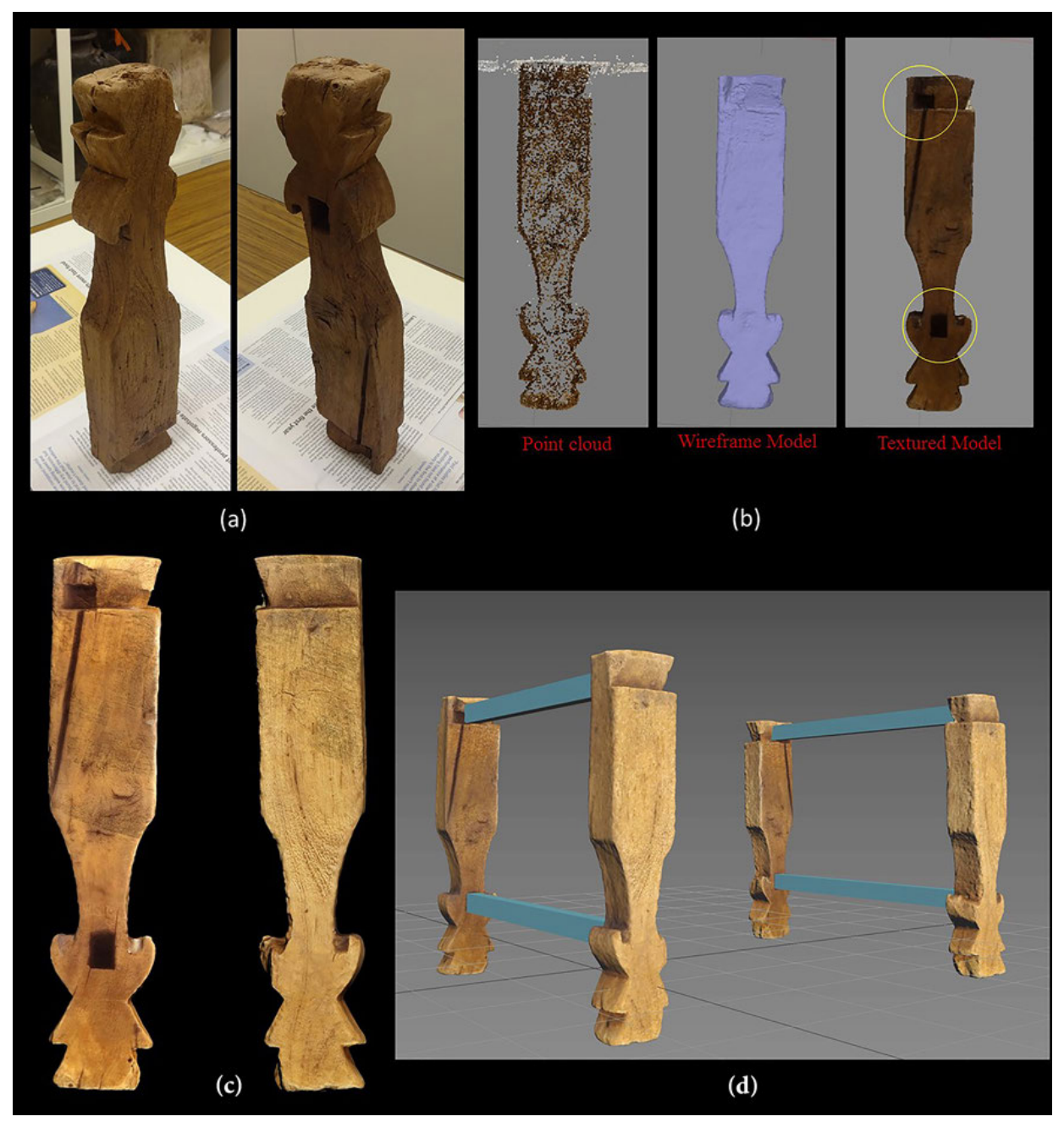

Figure 6. (a) A wooden fragment listed as chair leg; (b) Photogrammetric 3D modeling process from point cloud to textured model: (c) Low polygonal 3D model of the leg; (d) The first depiction of the 3D reconstructed stool leg, showing the difficulty in joining the four legs. 


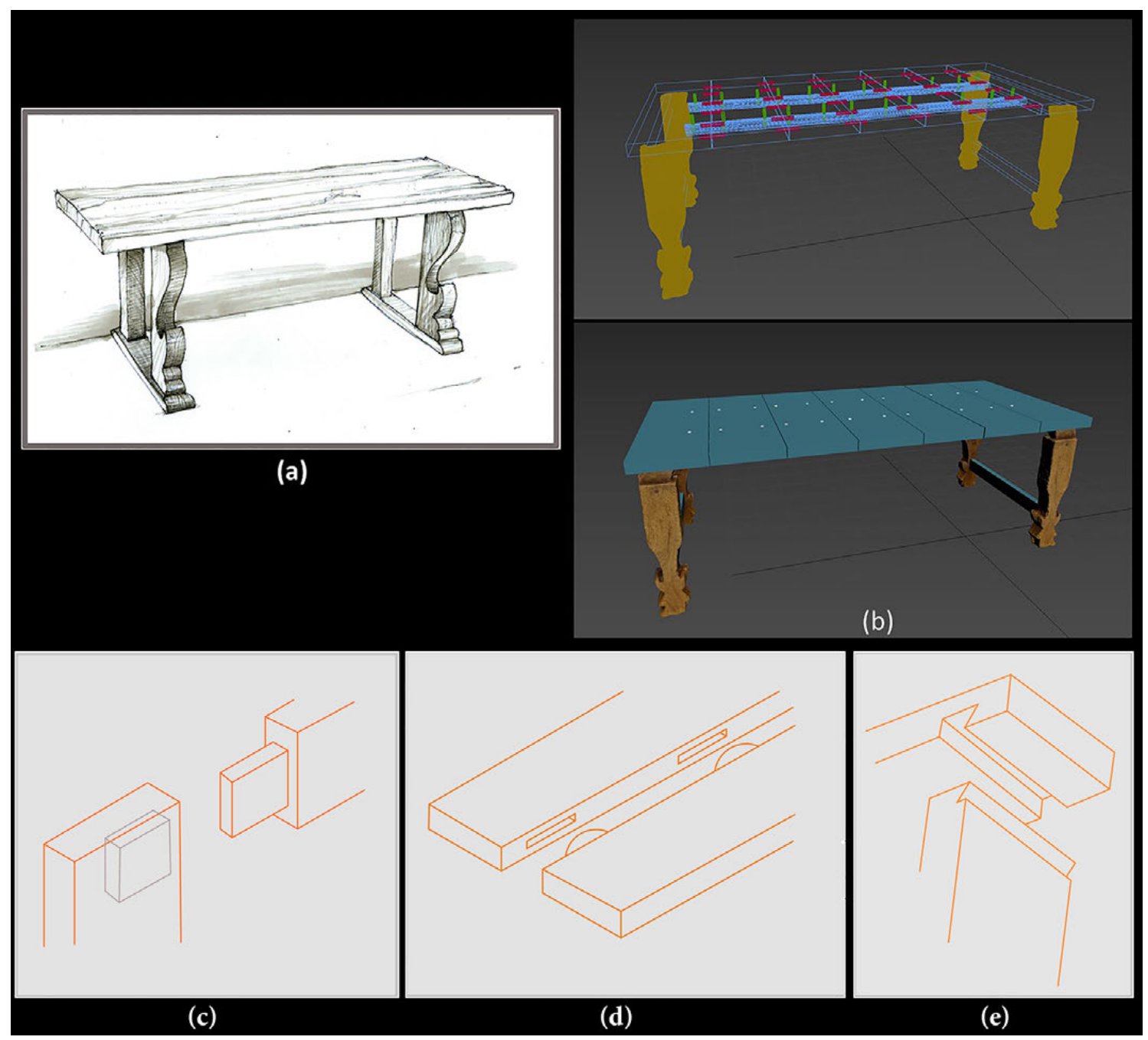

Figure 7. (a) A sketch of a reconstructed wooden bench from Herculaneum (after Croom 2007); (b) 3D reconstruction of bench; (c) Mortise and tenon for joining the front and back leg; (d) the biscuit joint for joining the wooden parallel blocks of the bench top, (e) the half dovetail dado for joining the leg with the top of the bench.

The lathed leg in Fig. $8 \mathrm{~g}$ also belongs to the C-level, and this type of stool leg was common in the Roman period. Chair legs evolved into a slender, round shape in ancient Egypt, beginning in the new Kingdom (18th dynasty) [Hayward 1981]. In Fig. 8a, the drawings on tombs show early use of bow drills [Scot 1965], which were used for making lathed wooden parts. The development of the lathed legs continued in the Greco-Roman period (Fig. 8b); the same method of mortise and tenon was still used to join the four perpendicular legs of the stool. However, the proportions and height were elongated in the Roman era, as is evident in the comparison between the Greek lathed leg in Fig. 8e, which is $38 \mathrm{~cm}$ in height, and the lathed leg from Karanis in Fig. $8 \mathrm{f}$ with a height of $43.5 \mathrm{~cm}$. 


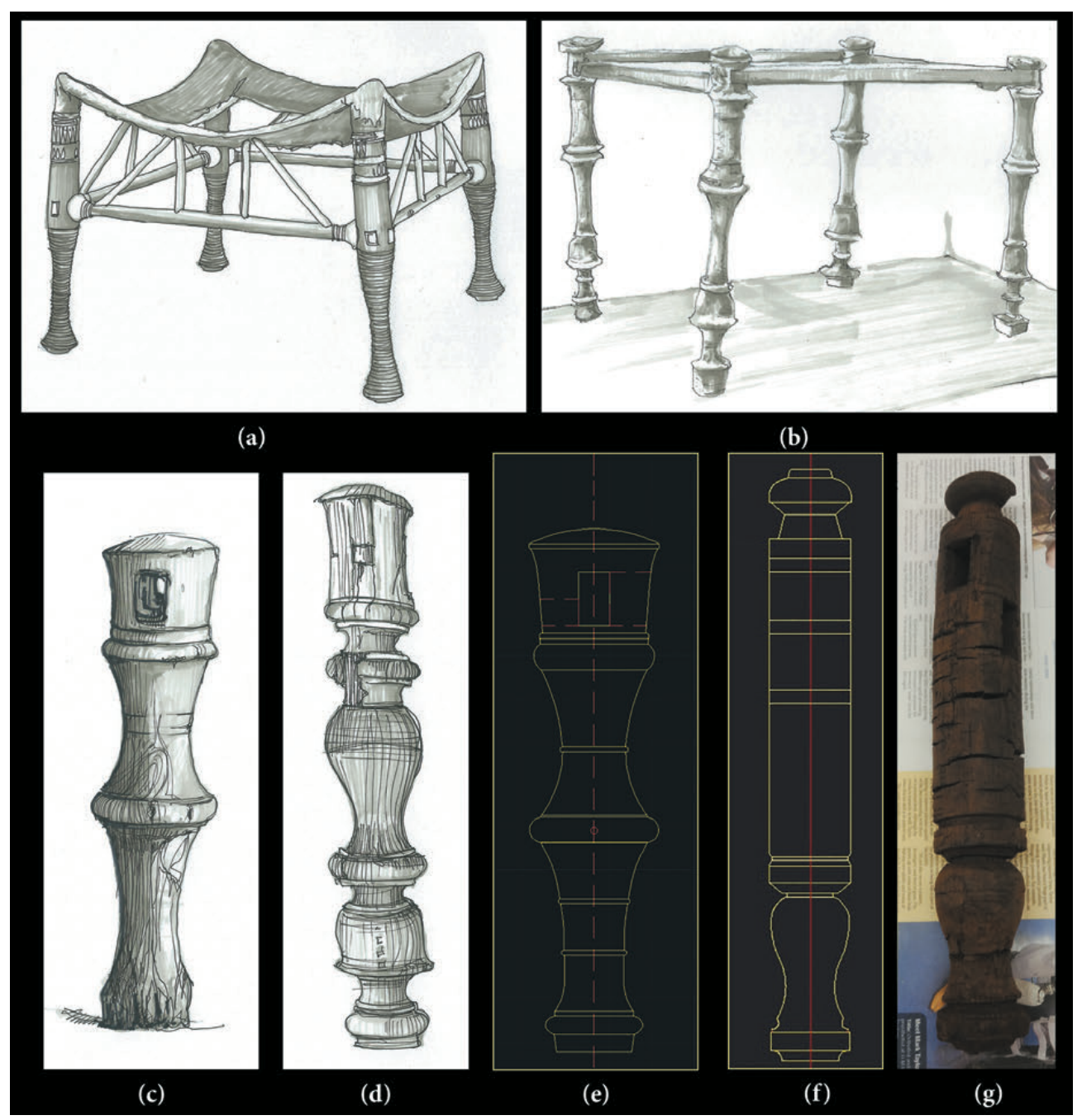

Figure 8 (a) A sketch of an ebony stool with ivory struts and inlaid ornament. New Kingdom. British Museum (after Hayward 1981); (b) A sketch of a reconstructed wooden stool. Berlin Museum (after Richter 1966); (c) A sketch of a Greek wooden stool leg found in Egypt. Metropolitan Museum of Art (after Richter 1966); (d) A sketch of a Roman wooden stool leg found in Rifeh Egypt. Metropolitan Museum of Art (after Richter 1966); (e) A CAD drawing of a Greek wooden leg; ( $f$ ) A CAD drawing of a lathed leg from Karanis, Egypt; $(g)$ A photograph of a lathed leg from Karanis.

The lathed leg from Karanis in Fig. 9a has two slits through the entire width of the leg, one lower than the other, so that made it easy to depict how the legs were connected using through mortise and tenon joints (Fig. 9c). The difference in levels between the two openings is similar to the Egyptian stool in Fig. 10c [Richter 1966]. The seating would have been woven in after the construction was finished. Parallels for such furniture webbing are ubiquitous [Wendrich 1999]. In the Pharaonic period stool seats were mostly woven with linen string. Greco-Roman chair and bed matting was made of twisted palm leaf, or string made of grass. 


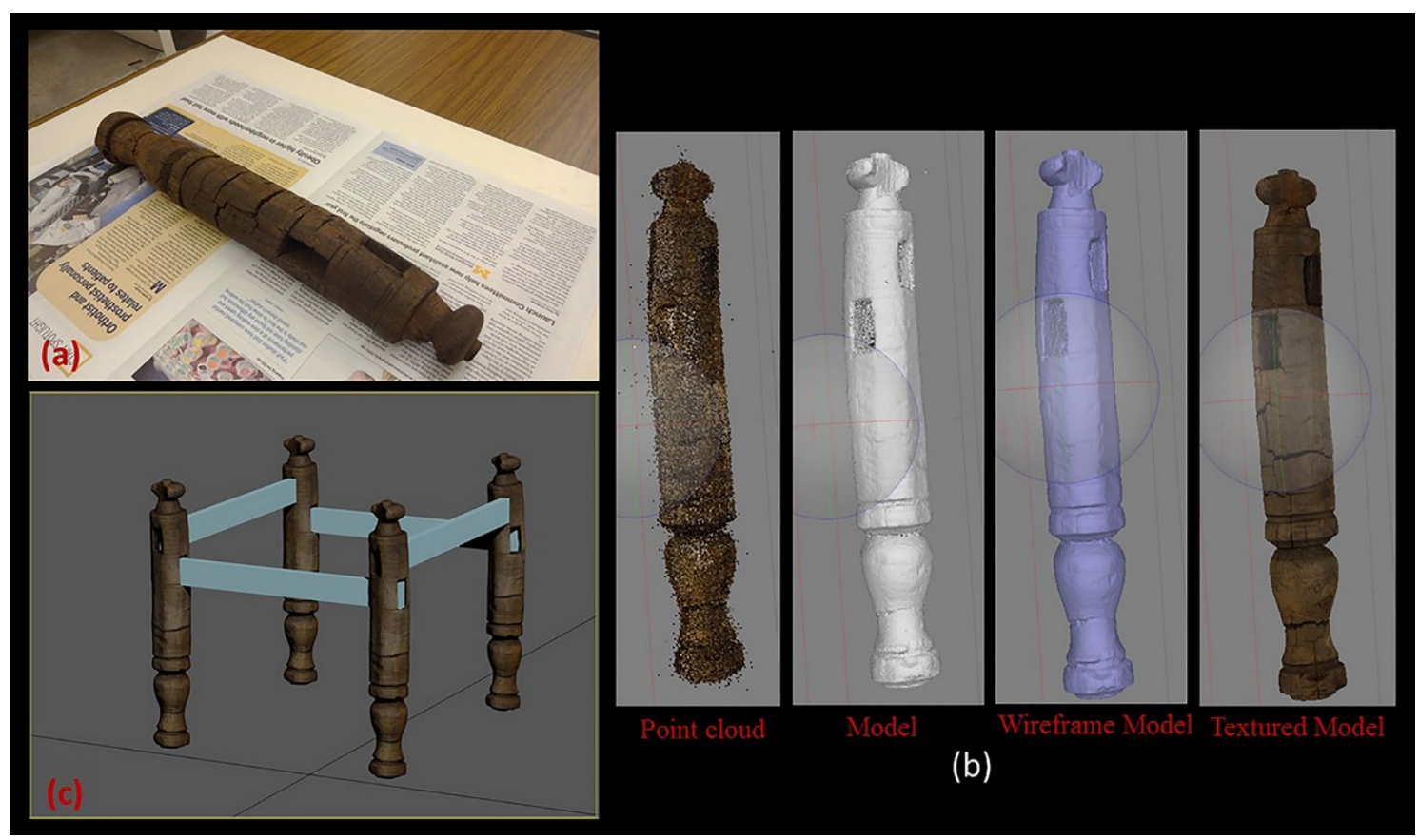

Figure 9 (a) lathed wooden leg from Karanis; (b) Photogrammetric 3D modeling process from point cloud to textured model; (c) 3D reconstruction of stool.

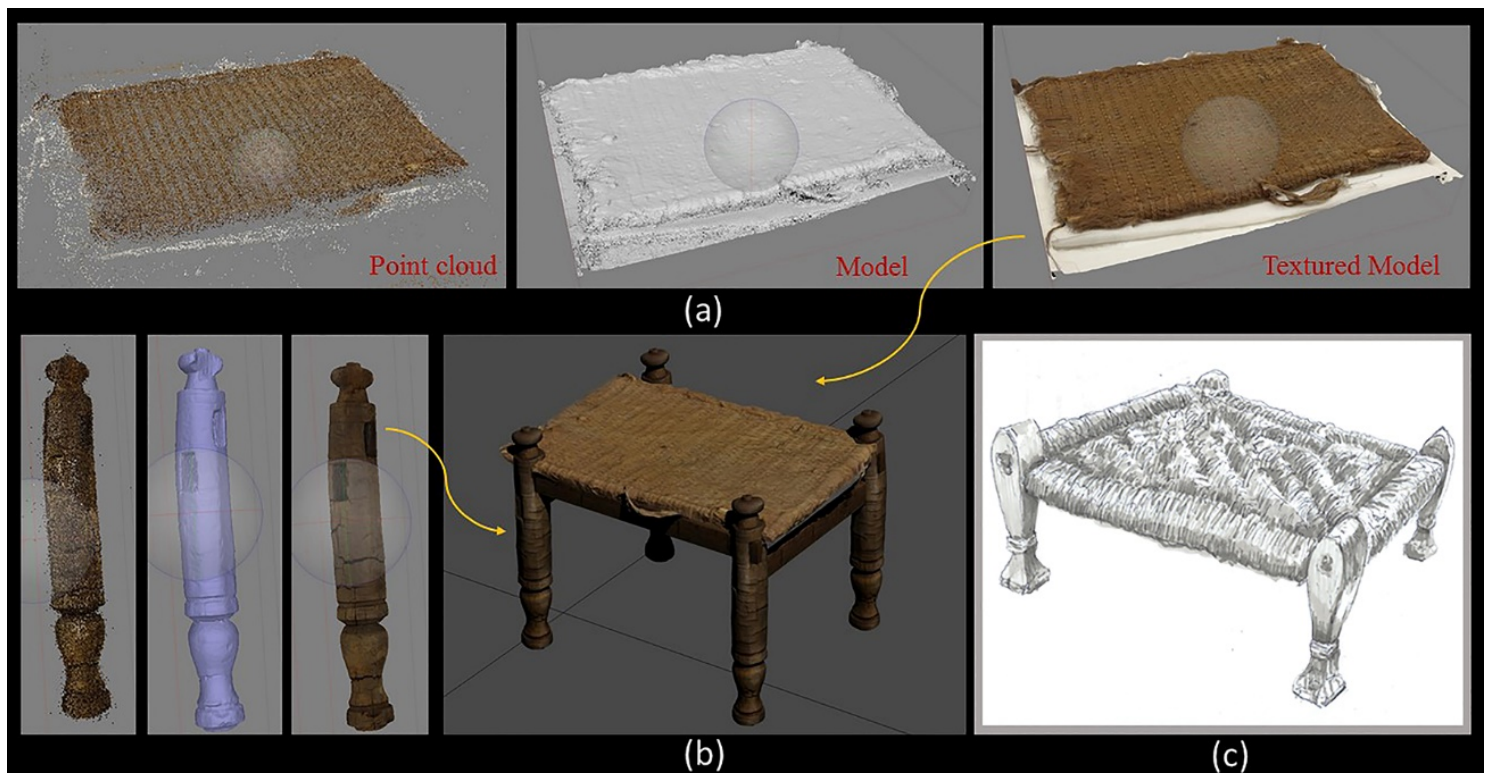

Figure 10 (a) Photogrammetric 3D modeling process from point cloud to textured model of the mat; (b) result of combining the 3D model of the mat with the reconstructed stool; (c) A sketch of an Egyptian stool with rush seat (after Richter 1966). 
The observation of the item in Fig. 10a is listed in the Kelsey Museum catalogue as a mat and belongs to the C-level. It has, however, a wooden internal frame and strings in the corner of the matting, and could have been, therefore, a re-use of furniture matting, as shown in Fig. 10b. The technique, widely spaced twining, however, is not commonly used in furniture from either the Pharaonic, or the GrecoRoman periods in Egypt.

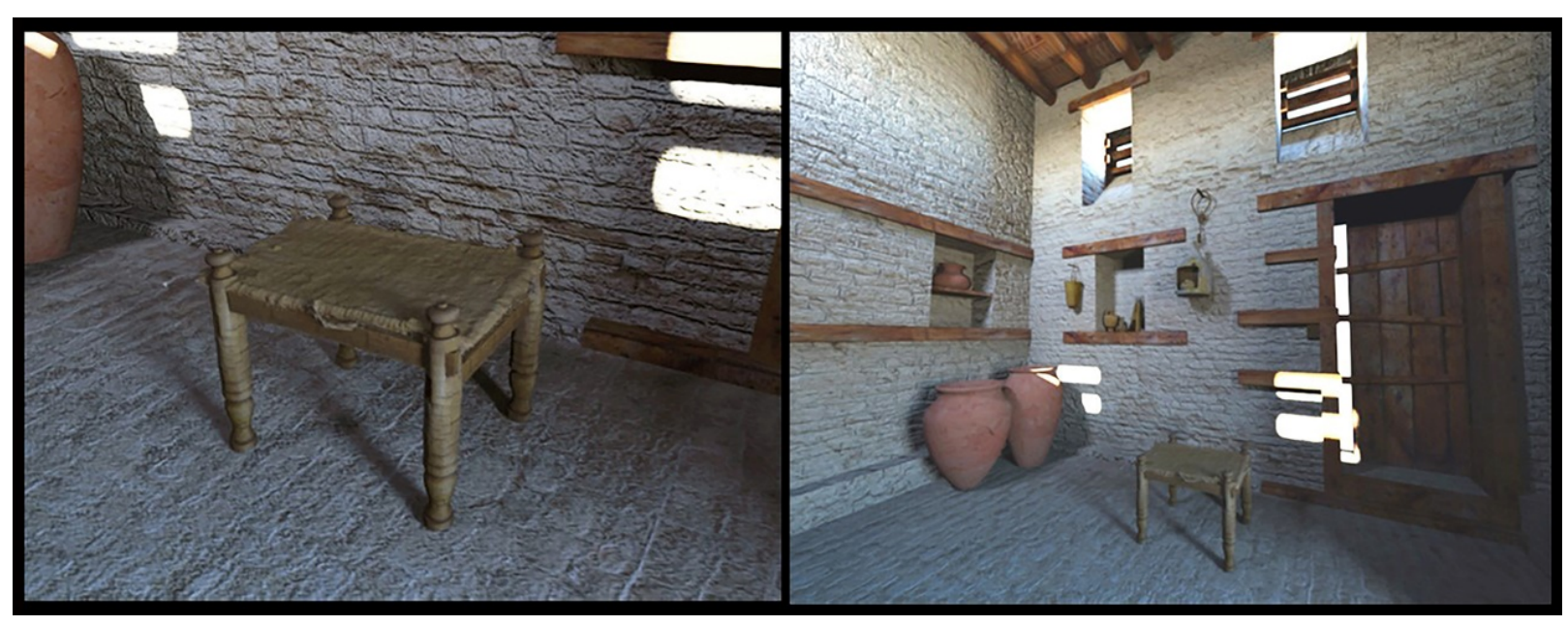

Figure 11. Final reconstructed stool placed inside a virtual 3D model of a Karanis house.

\subsection{Beds}

Just as the stools, beds were made as a wooden frame, woven in with matting. The warp was wound along the length of the bed, with grass string or twisted palm leaf, after which the weft would have been woven in at a perpendicular angle. Parallels of bed webbing from Qasr Ibrim show elaborate decorative weaving patterns [Wendrich 1999]. The bed fragment found at Karanis has a height of 61 $\mathrm{cm}$ and a width of $97 \mathrm{~cm}$ (Fig. 13a); it was from a house assigned to the B-level. The legs have two big slits that go through the entire width of the wood, a connection that is known as the through mortise and tenon. This would connect the foot and header into a frame in which either the bed matting was woven in, or, rarely, wooden slats were fastened. An example of the latter construction was found in a late second-century child's grave in Hawara, Egypt, as shown in Fig. 13c [Croom 2007]. The 3D reconstruction (Fig. 14) visualizes the missing parts of the bed, here surmised to have been slats to support a mattress. In most modest, lower class, homes, however, people would have used sleeping mats, which could have been rolled out anywhere in the house, instantly changing the function of a space into sleeping quarters. 


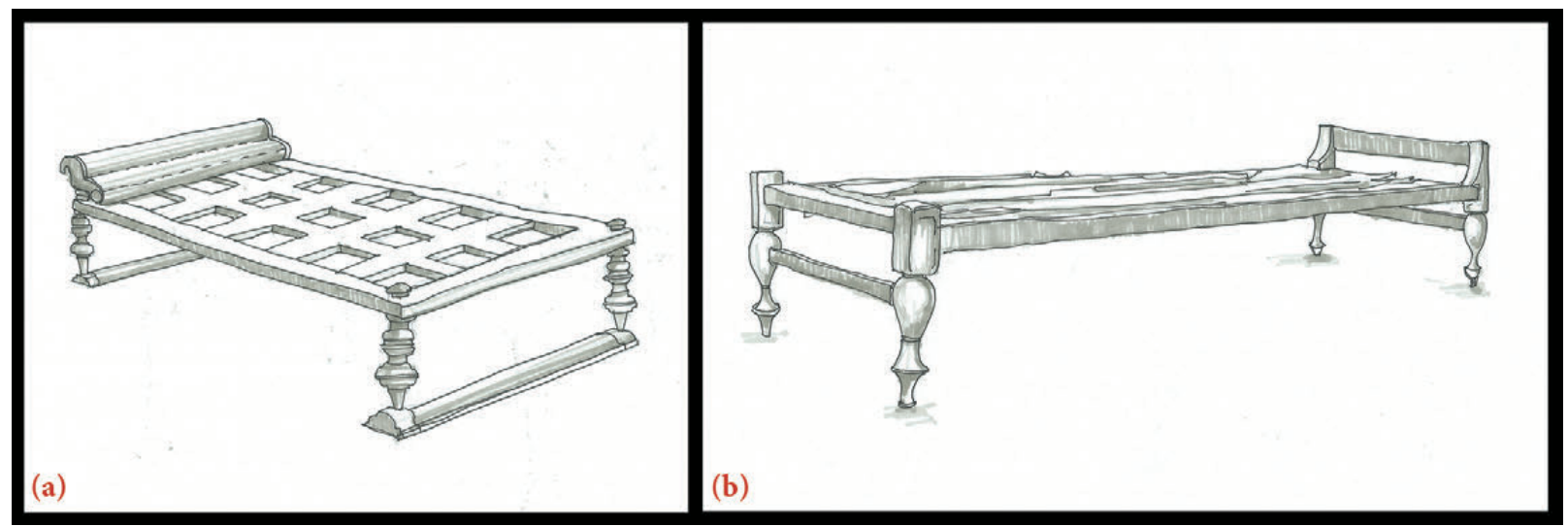

Figure 12. (a) A sketch of a typical Roman bed (after Croom 2007); (b) A sketch of a wooden bed found in Egypt. Berlin Museum (after Richter).

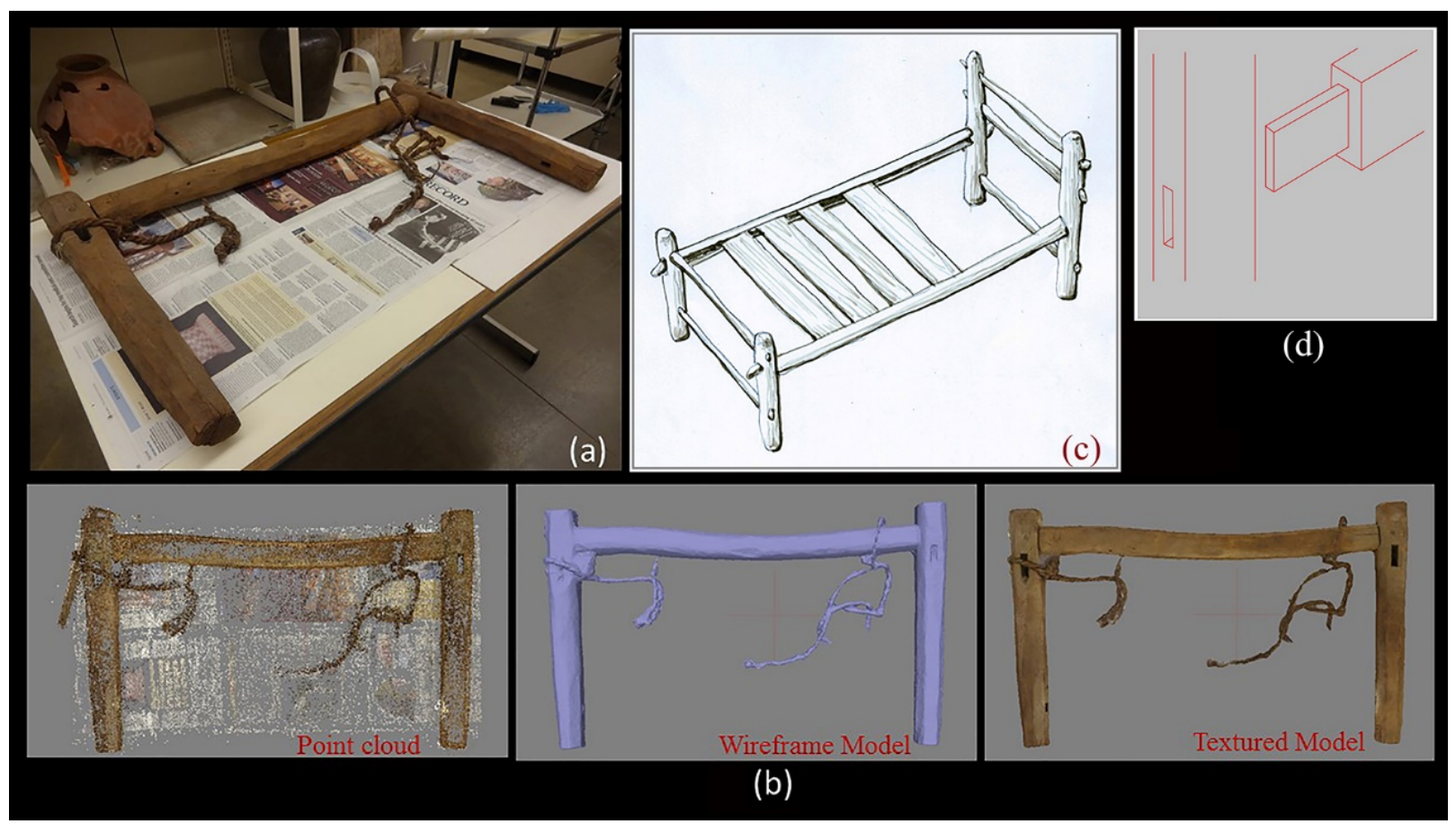

Figure 13. (a) Bed back from Karanis; (b) 3D Photogrammetric model; (c) A sketch of a frame bed from Hawara, Egypt (after Croom 2007); (d) Through mortise \& tenon joint. 


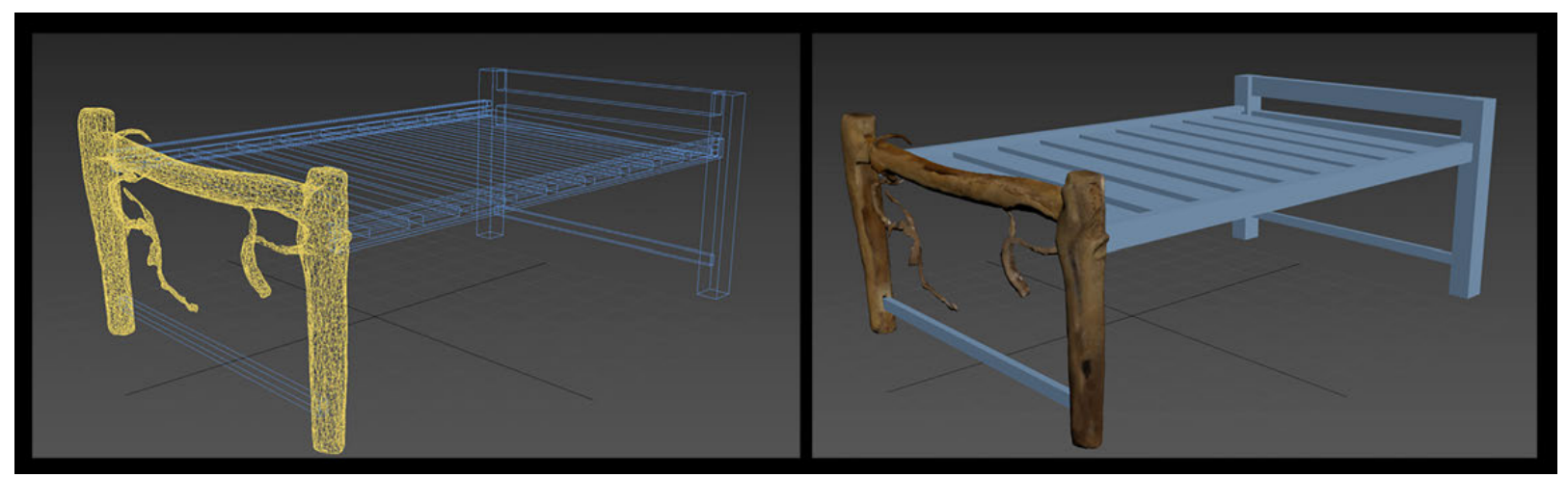

Figure 14. Final 3D reconstruction of the bed model.

\subsection{Tables}

\subsubsection{Tripod tables}

On an earthen or mud-brick surface, the flooring type of most houses in Karanis, the best way to provide stability for tables is to use three legs. The table top type that has evidence for a tripod was very common in Karanis. The one in Fig. 15b is small, with a diameter of $31 \mathrm{~cm}$, and was found in the B level. The closest parallel to this piece is a tripod table from Fayum, Egypt (Fig. 15a). The lathed leg in Fig. 15c has two rough endings at the top and bottom which suggest that it supported a top, but also had a base to support and balance the table similar to the "Greek table" from Luxor in Fig. 16a [Richter 1966].

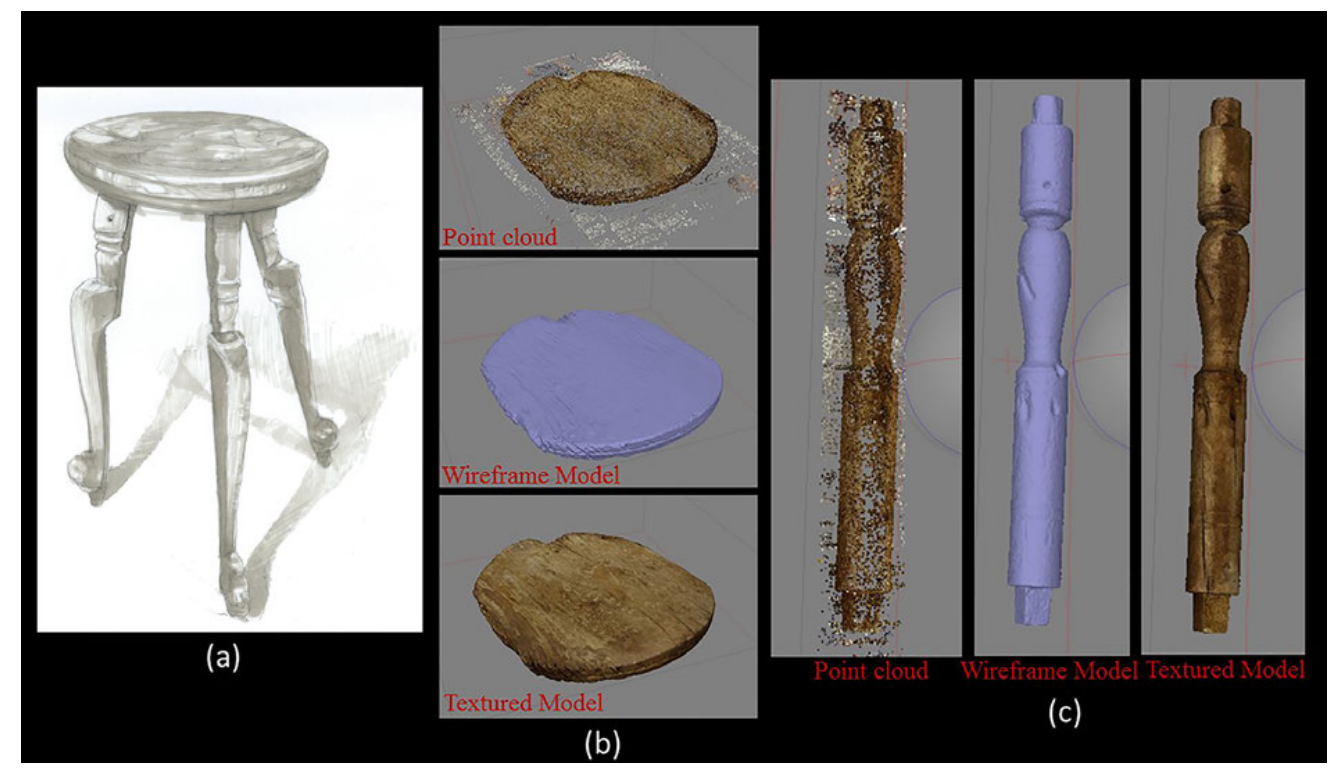

Figure 15. (a) A sketch of a tripod table from Fayum (after Wilfong 2004); (b) Photogrammetric 3D model of the table top; (c)Photogrammetric 3D model of lathed leg. 


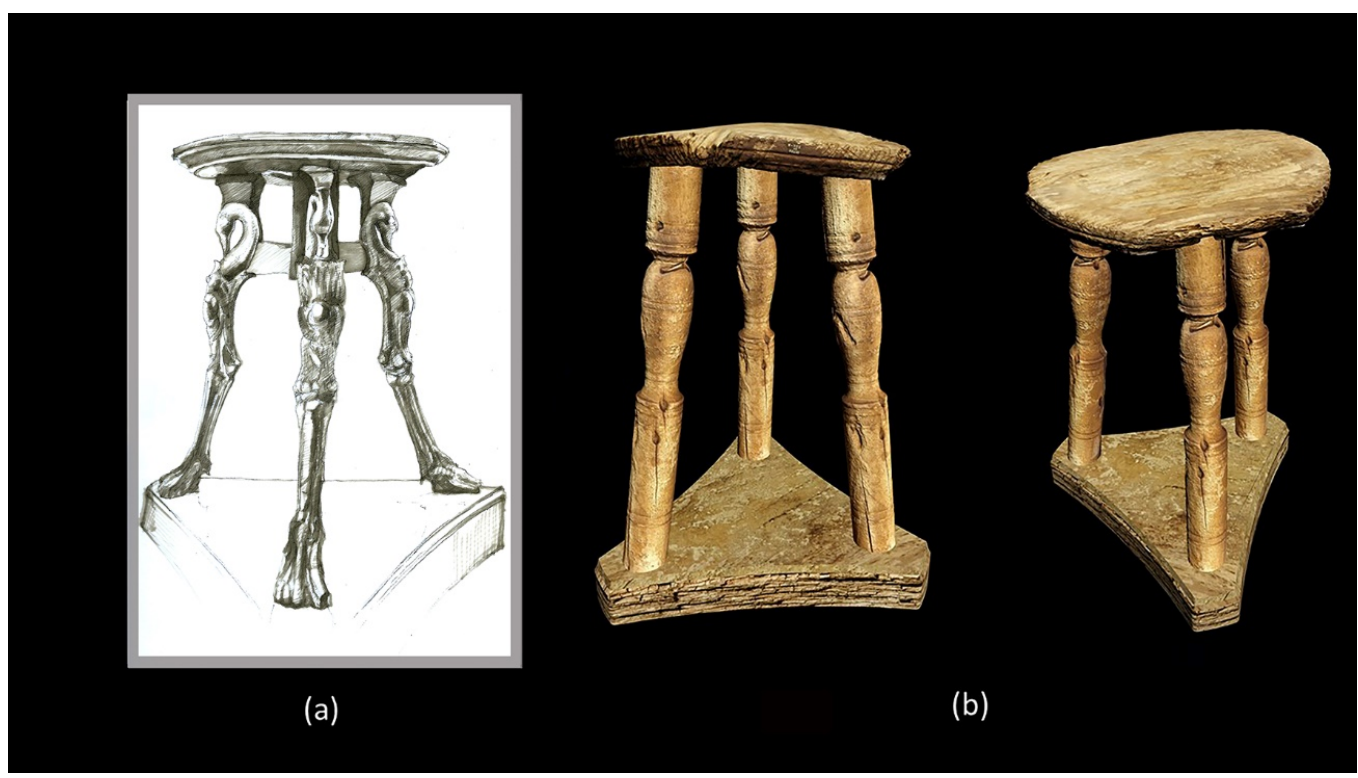

Figure 16. (a) A sketch of a Greek table from Luxor (after Richter 1966); (b) Final 3D reconstructed tripod table model.

The small rectangular table top in Fig. 17a was found in the B level. Its dimensions are 48 by $38 \mathrm{~cm}$, and it has three holes to fit the legs. It is also obvious that dowel plugs were used to connect the two wooden planks that make up the table top (Fig. 17c). The table top is strengthened with two wooden cross beams. The 3D reconstruction in Fig. 18b) visualizes the complete table after adding the missing legs.

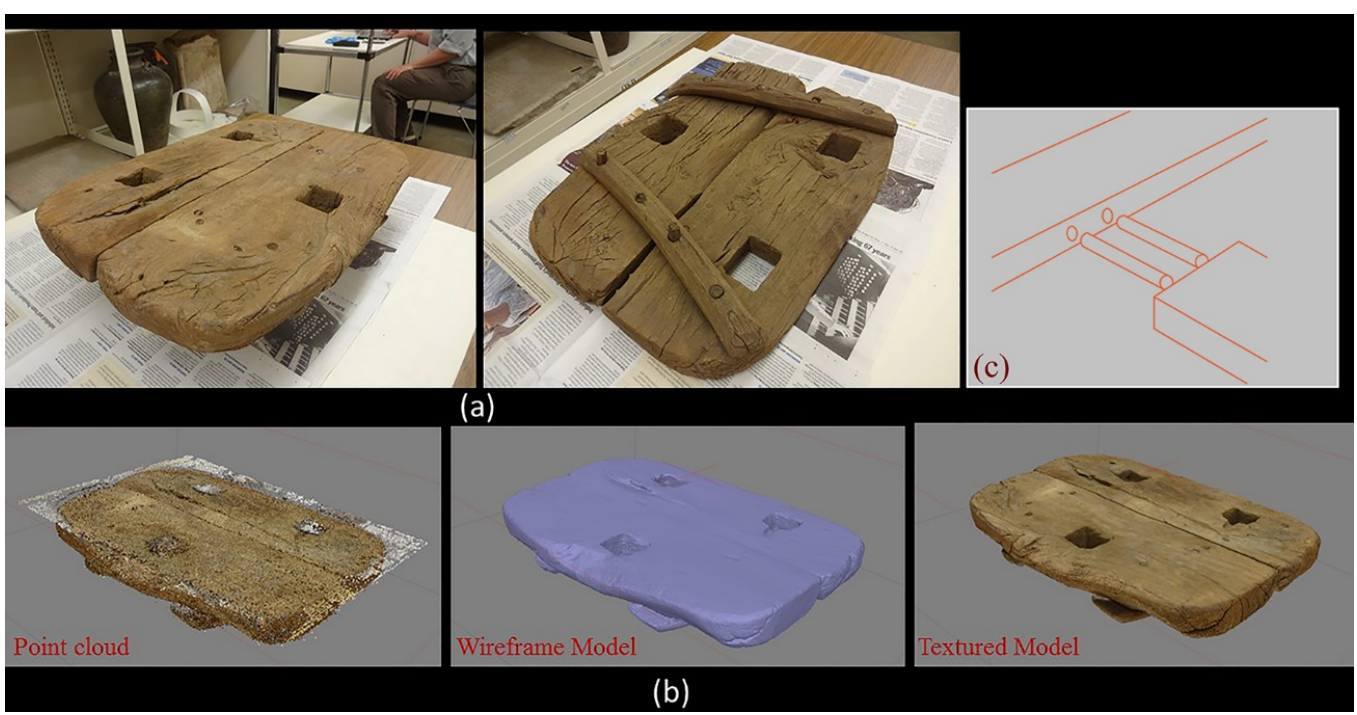

Figure 17. (a) rectangular table top; (b) Photogrammetric 3D model of table top; (c) illustration of the wooden dowels connecting the blocks of the table top. 


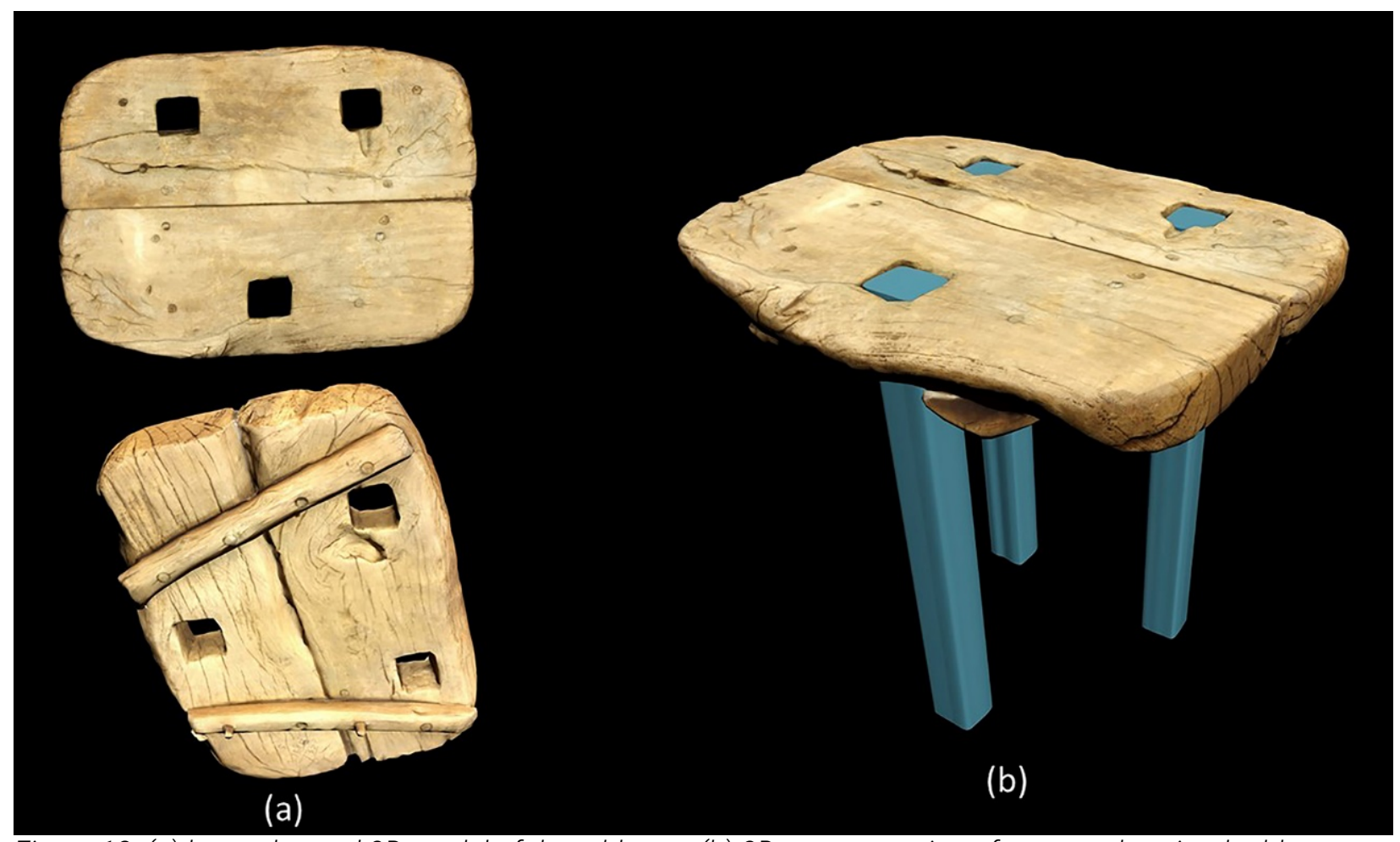

Figure 18. (a) low-polygonal 3D model of the table top; (b) 3D reconstruction of rectangular tripod table.

\subsubsection{Four-legged Tables}

The table top in Fig. 19a belongs to the A-level, which is the most recent level of occupation. It is an example of the use of a dowel plug to connect the wooden planks (Fig. 19b). Since the table top is larger than the previous models, and its size makes it unlikely that it is a tripod table, we turn to evidence for alternatives. Wall paintings from Herculaneum show four-legged tables and the 3D reconstruction is based on the same concept. Fig. 20 visualizes the complete table after adding the missing part of the table top and legs.

\section{CONCLUSION}

In this paper, we aimed at investigating the potentials of digital technology for the reconstruction of ancient furniture, based on different lines of evidence, ranging from physical remains, to skeuomorphs, wall paintings and parallels from Egypt, Greece and Rome. The reconstruction of the wooden furniture in the Greco-Roman town Karanis might help with the interpretation of wooden elements in museum collections. It also provides an overview of the technical solutions and wood working traditions that give us precious information for the interpretation of furniture outside Egypt in the Greco-Roman world, of which we only have scant depictions, but no physical remains. Furthermore, creating the model clarifies what types of reconstructions are feasible, or more likely than others. Placing the furniture back in its context aids in better understanding the use of space and interior decoration of lived-in spaces. 


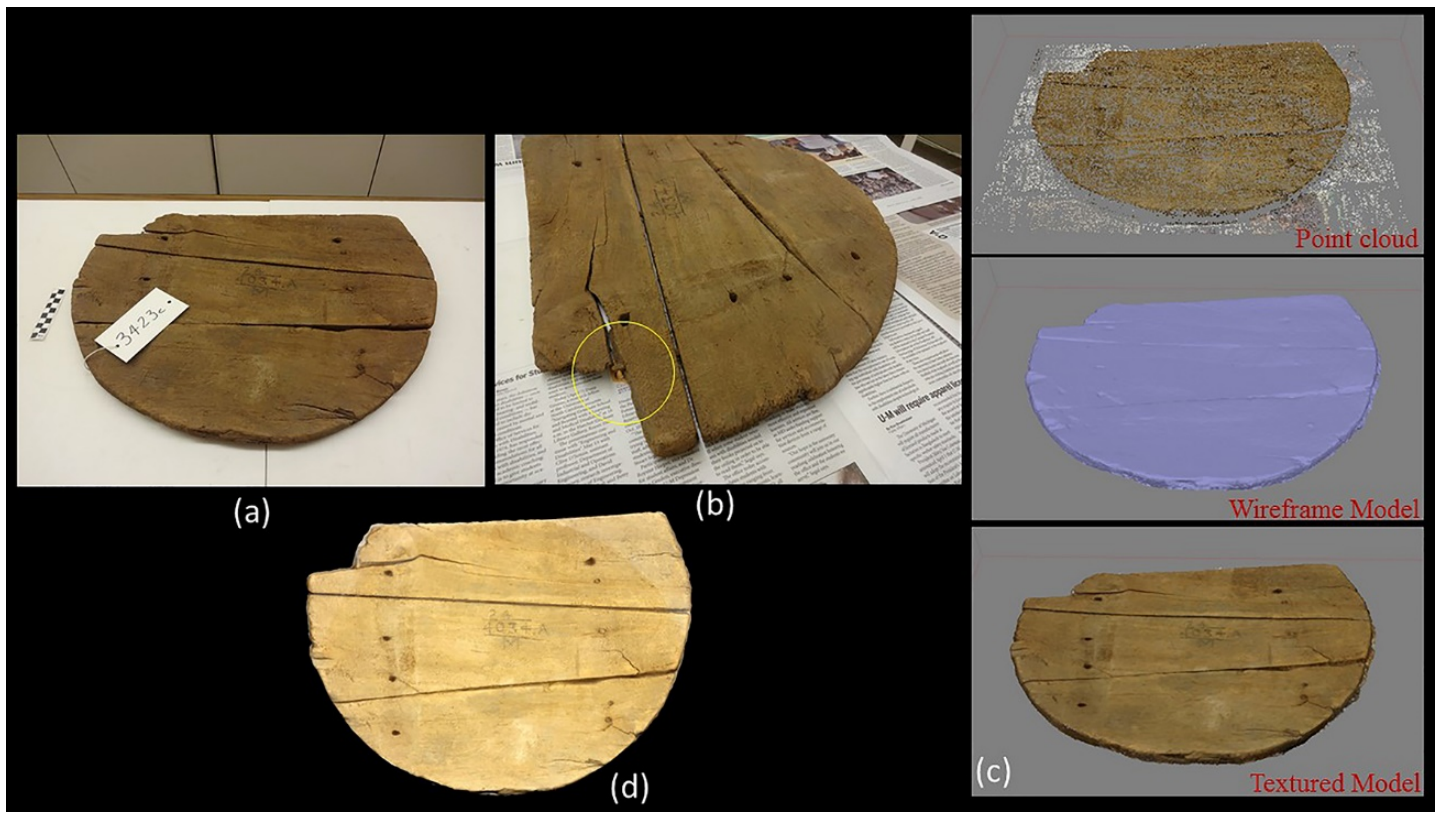

Figure 19. (a) table top from Karanis; (b) Photogrammetric 3D modeling process from point cloud to textured model; (c) dowel plugs connecting the wooden blocks of the table top; d) low polygonal table top.

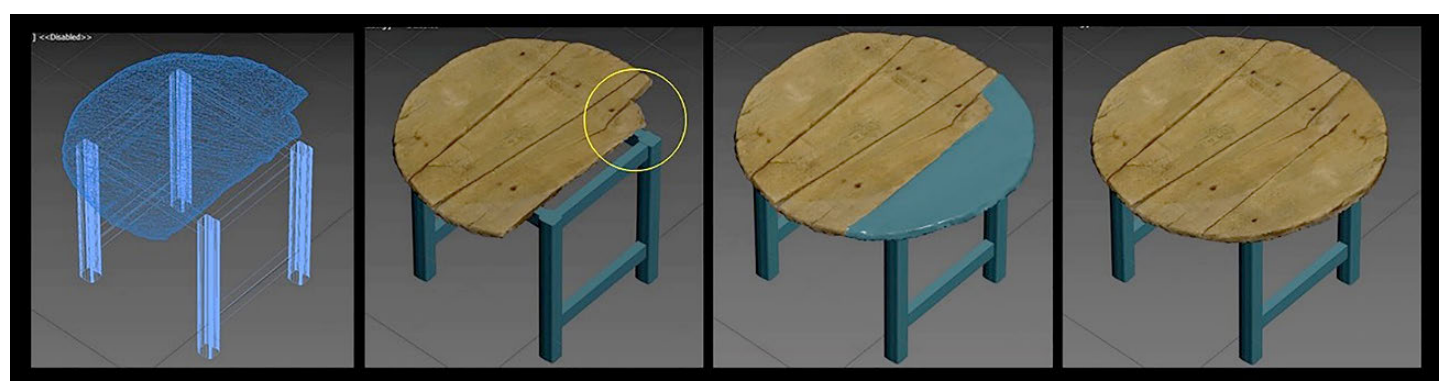

Figure 20. 3D reconstruction process of round table.

\section{FUTURE WORK}

We intend to move towards a new phase of this research, aiming at utilizing the resulting 3D reconstructed models to re-create real size wooden models of some selected furniture pieces to be manufactured using the same types of original materials and paint finishes used in Karanis and constructing them with the traditional installation methods. This study aims to record the construction workflow which was carried out by the ancient manufacturer in this period. 


\section{ACKNOWLEDGEMENT}

The author gratefully acknowledges Dr. Willeke Wendrich for her guidance and support during the course of performing this research, and for her valuable comments and suggestions.

\section{REFERENCES}

Hans Barnard et al. 2016. The Preservation of Exposed Mudbrick Architecture in Karanis (Kom Aushim), Egypt. Journal of Field Archaeology. 40, 3 (2016), 84-100.

Alexander Croom. 2007. Roman Furniture. Stroud: Tempus Publishing.

Eiman Elgewely and Willeke Wendrich. 2015a. Reviving Karanis in 4D: Reconstruction of Space through Time. In Cultural Heritage and New Technologies 20. Vienna, Nov. 2-4, 2015.

Eiman Elgewely and Willeke Wendrich. 2015b. Virtually United in Real Time: Museum Collections and Archaeological Context Explored. In Digital Heritage Congress. Granada: IEEE.

Helena Hayward. 1981. World Furniture. London: Hamlyn.

Elinor Husselman. 1957. Donationes Mortis Causa from Tebtunis. Trans. Proc. Am. Philol. Assoc. 88 (1957), 135-154.

Elinor Husselman. 1979. Karanis Excavations of the University of Michigan in Egypt, 1928-1935. Topography and Architecture: A Summary of the Reports of the Director, Enoch E. Peterson. Ann Arbor: University of Michigan Press.

Geoffrey Killen. 1979. Ancient Egyptian Furniture I. Aris \& Phillipps.

Geoffrey Killen. 1994. Ancient Egyptian Furniture II. Aris \& Phillipps.

Stephan Mols. 2008. Ancient Roman Household Furniture and Its Use : From Herculaneum To the Rhine. AnMurcia 23-24, May 2009 (2008), 145-160.

Stephan Mols. 1999. Wooden Furniture in Herculaneum: Form, Technique and Function. Amsterdam: Gieben.

Gisela Richter. 1966. The Furniture of the Greeks, Etruscans, and Romans. London: Phaidon.

Nora Scot. 1965. Our Egyptian Furniture. Metropolitan Museum of Art Bulletin, n. s. 24 (1965).

Roger Ulrich. 2007. Roman Woodworking.New Haven: Yale University Press.

Willeke Wendrich. 1999. The World According to Basketry; an Ethnoarchaeological Interpretation of Basketry Production in Egypt, Leiden: Research School for Asian, African and Amerindian Studies (CNWS).

Terry Wilfong. 2004. Karanis, An Egyptian Town in Roman Times: Discoveries of the University of Michigan Expedition (1924-1935). Elaine Gazda, ed., Kelsey Museum Publications.

Received March 2017; revised July 2017; accepted August 2017. 